
Not for reproduction, distribution or commercial use.

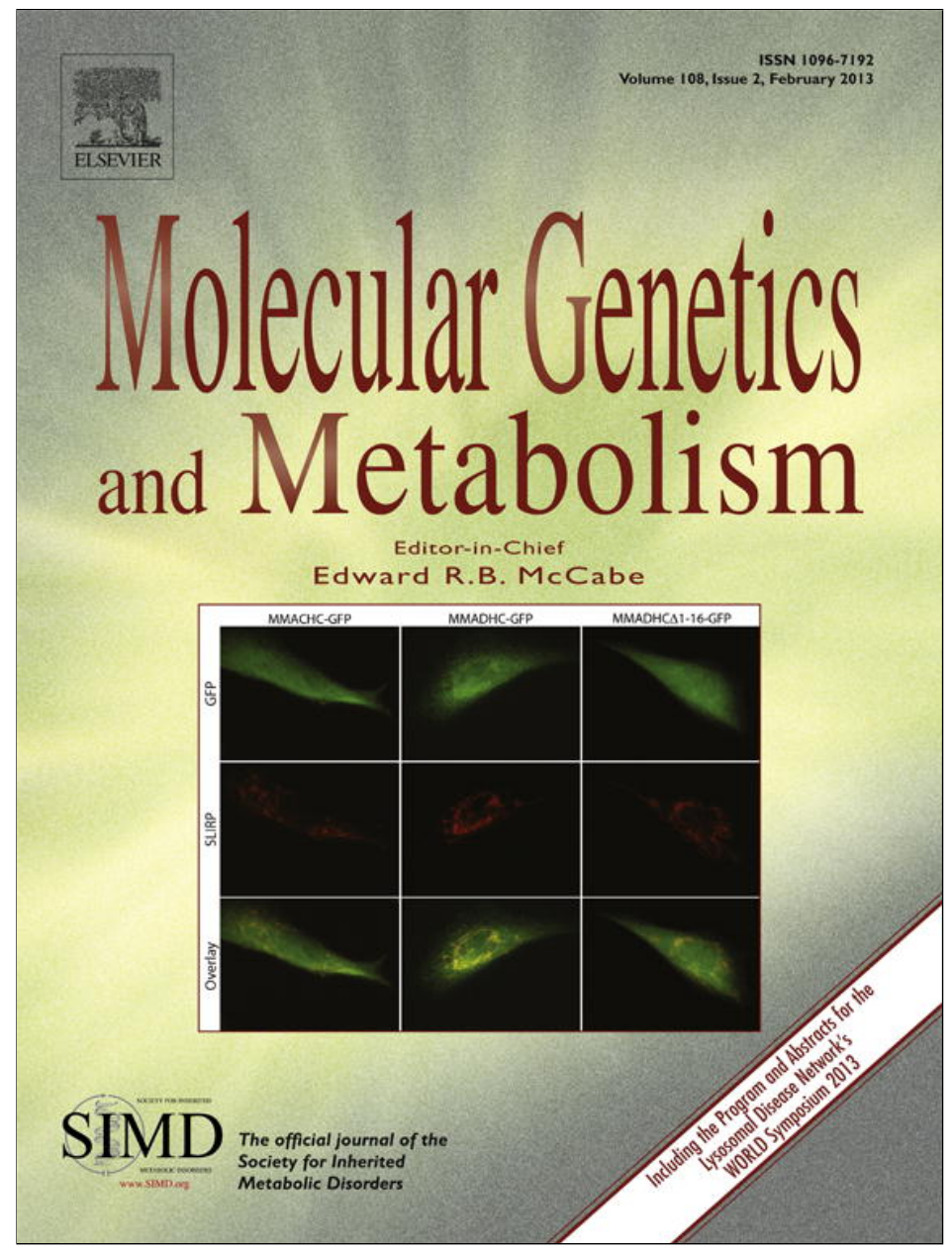

This article appeared in a journal published by Elsevier. The attached copy is furnished to the author for internal non-commercial research and education use, including for instruction at the authors institution and sharing with colleagues.

Other uses, including reproduction and distribution, or selling or licensing copies, or posting to personal, institutional or third party websites are prohibited.

In most cases authors are permitted to post their version of the article (e.g. in Word or Tex form) to their personal website or institutional repository. Authors requiring further information regarding Elsevier's archiving and manuscript policies are encouraged to visit:

http://www.elsevier.com/copyright 
Brief Communication

\title{
Alglucosidase alfa enzyme replacement therapy as a therapeutic approach for glycogen storage disease type III
}

\author{
Baodong Sun ${ }^{\text {a,* }}$, Keri Fredrickson ${ }^{\text {a }}$, Stephanie Austin ${ }^{\text {a }}$, Adviye A. Tolun ${ }^{\mathrm{a}, 1}$, Beth L. Thurberg ${ }^{\mathrm{b}}$, \\ William E. Kraus ${ }^{c, d}$, Deeksha Bali ${ }^{\text {a }}$, Yuan-Tsong Chen ${ }^{\text {a }}$, Priya S. Kishnani ${ }^{\text {a }}$ \\ a Division of Medical Genetics, Department of Pediatrics, Duke University Medical Center, Durham, NC, USA \\ b Department of Pathology, Genzyme, a Sanofi Company, Framingham, MA, USA \\ c Department of Cell Biology, Duke University Medical Center, Durham, NC, USA \\ d Department of Medicine, Duke University Medical Center, Durham, NC, USA
}

\section{A R T I C L E I N F O}

\section{Article history:}

Received 4 December 2012

Received in revised form 18 December 2012

Accepted 18 December 2012

Available online 27 December 2012

\section{Keywords:}

Alglucosidase alf

Glycogen storage disease type III

Glycogen degradation

Primary skeletal muscle culture

Novel therapy

\begin{abstract}
A B S T R A C T
We investigated the feasibility of using recombinant human acid- $\alpha$ glucosidase (rhGAA, Alglucosidase alfa), an FDA approved therapy for Pompe disease, as a treatment approach for glycogen storage disease type III (GSD III). An in vitro disease model was established by isolating primary myoblasts from skeletal muscle biopsies of patients with GSD IIIa. We demonstrated that rhGAA significantly reduced glycogen levels in the two GSD IIIa patients' muscle cells (by $17 \%$ and $48 \%$, respectively) suggesting that rhGAA could be a novel therapy for GSD III. This conclusion needs to be confirmed in other in vivo models.
\end{abstract}

(c) 2012 Elsevier Inc. All rights reserved.

\section{Introduction}

Glycogenolysis is the major glycogen degradation pathway that involves two cytoplasmic enzymes, glycogen phosphorylase (EC 2.4.1.1) and glycogen debranching enzyme (GDE) [1]. GDE has two independent catalytic activities at different sites on the protein: a 4-alphaglucotransferase (EC 2.4.1.25) activity and an amylo-1, 6-glucosidase (EC 3.2.1.33) activity. Deficiency of GDE in GSD III results in incomplete glycogenolysis and the accumulation of abnormally structured cytoplasmic glycogen in multiple tissues, mainly in liver and muscle. There is a significant clinical variability in GSD III caused by different mutations in the AGL gene. Most patients have both muscle and liver involvement (type IIIa) although some have only liver symptoms (type IIIb) $[2,3]$. Progressive liver disease with resultant liver fibrosis/cirrhosis and liver failure, myopathy, and cardiomyopathy is a major cause of morbidity and mortality in adult patients. Currently, other than symptomatic management of hypoglycemia and diet interventions, there is no effective treatment for this disease [4].

Abbreviations: GSD III, glycogen storage disease type III; rhGAA, recombinant human acid- $\alpha$ glucosidase.

* Corresponding author at: Division of Medical Genetics, Department of Pediatrics, Duke University Medical Center, 595 Lasalle Street, GSRB1 Building, 4th Floor, Room 4044, PO Box DUMC 103856, Durham, NC 27710, USA. Fax: + 19196840923.

E-mail address: baodong.sun@duke.edu (B. Sun).

1 Present address: Laboratory Corporation of America, RTP, NC, USA.
In addition to the cytosolic glycogenolysis pathway, there is a small percentage of cellular glycogen continually trafficking into the lysosomes and hydrolyzed by the enzyme acid $\alpha$-glucosidase (GAA, EC 3.2.1.20) [1]. This minor glycogen degradation pathway through lysosomes plays an important role in overall glycogen metabolism because deficiency of GAA causes Pompe disease (GSD II), resulting in an extensive lysosomal glycogen accumulation in skeletal muscle, heart, and the central nerve system [3]. Enzyme replacement therapy (ERT) with recombinant human GAA (rhGAA) is an FDA approved therapy for Pompe disease. We hypothesize that the administration of rhGAA will enhance lysosomal glycogen depletion, facilitate glycogen transport into lysosomes, and ultimately reduce cytoplasmic glycogen accumulation in GSD III. In this study, we tested our hypothesis in a cellular model of GSD III.

\section{Materials and methods}

Needle skeletal muscle biopsies were obtained from two GSD IIIa patients, a 45 year old male (patient 1, Pt-1) and a 35 year old female (patient 2, Pt-2) at the metabolic clinic of Duke University Medical Center under an institutional review board approved protocol. The diagnosis of GSD IIIa was previously made based on undetectable GDE enzyme activity in their muscle biopsies and two confirmed mutations in the AGL gene at the Duke GSD Laboratory (unpublished data). One-third of each sample was fixed in cold 3\% glutaraldehyde for electron microscopy (EM) and high resolution light microscopy 
(HRLM) [5]. The remaining tissues were freshly placed in cold DMEM (GIBCO) for the isolation of myoblasts using a standard protocol [6]. The isolated myoblasts were expanded and maintained in high-serum growth medium at $37{ }^{\circ} \mathrm{C}$ in a humidified atmosphere of $5 \% \mathrm{CO}$.

Third-passage myoblasts were seeded onto collagen-coated $10-\mathrm{cm}$ dishes in growth medium (Day 1). When cells reached 70-80\% confluence (Day 4), differentiation into myotubes (myogenesis) was induced by changing to low-serum differentiation medium [6]. Muscle cells were harvested at different time points (Days 1, 4, 7, 10,15, and 23) to determine the best treatment time based on glycogen accumulation pattern. A glucose starvation experiment was conducted from Day 13 to Day 15 by removing glucose from medium [7]. For rhGAA treatment, $100 \mu \mathrm{g}$ of rhGAA (provided by Genzyme) was added to the culture medium $(10 \mathrm{ml})$ on Day 13. After $48 \mathrm{~h}$, cells were washed 3 times with cold phosphate buffered saline (PBS) and then collected with a scraper GAA activity and glycogen content were determined in the cell lysates as previously described [8].

\section{Results}

Light microscopic appearance of the patient skeletal muscle biopsies showed abundant, non-membrane-bound glycogen in cytoplasmic pools (Fig. 1A). Under EM, the vast majority of the glycogen was found free in the cytoplasm (not shown) along with a small amount of membrane-bound glycogen (Fig. 1B). Fusion of myoblasts forms large, multinucleated myotubes which mature into myofibers. Long and often branched myotubes were present 3 days (Day 7) after incubation in low-serum differentiation medium. By Day 10, most cells fused into myotubes (not shown). Glycogen content gradually decreased from Day 1 to Day 10, then started to increase and peaked at Day 15 (Fig. 1C). Glucose starvation was conducted from Day 13 to Day 15 and glycogen levels decreased by $28 \%$ and $49 \%$, respectively, in the two patient cells, in contrast to an $87 \%$ reduction in the normal control cells (Fig. 1D). This indicates incomplete glycogenolysis in the patient cells due to the lack of GDE enzyme activity.

Forty-eight hours after adding rhGAA treatment, GAA activity in medium was decreased from $1905 \pm 29(\mathrm{nmol} / \mathrm{h} / \mathrm{ml})$ on Day 13 to $19 \pm 1$ $(\mathrm{nmol} / \mathrm{h} / \mathrm{ml})$ on Day 15 . In cells, GAA activity was slightly increased for patient 1 but significantly higher for the normal control and patient 2 after rhGAA treatment (Fig. 1E). Interestingly, glycogen content was reduced significantly in both normal (by $35 \%$ ) and the two patients (by $17 \%$ for Pt- 1 and $48 \%$ for Pt-2, respectively) cells (Fig. 1F).

\section{Discussion}

Muscle and liver are major affected tissues in human patients with GSD III. Progression of disease can result in patients being wheel chair bound, with end stage liver cirrhosis and severe cardiomyopathy [4].
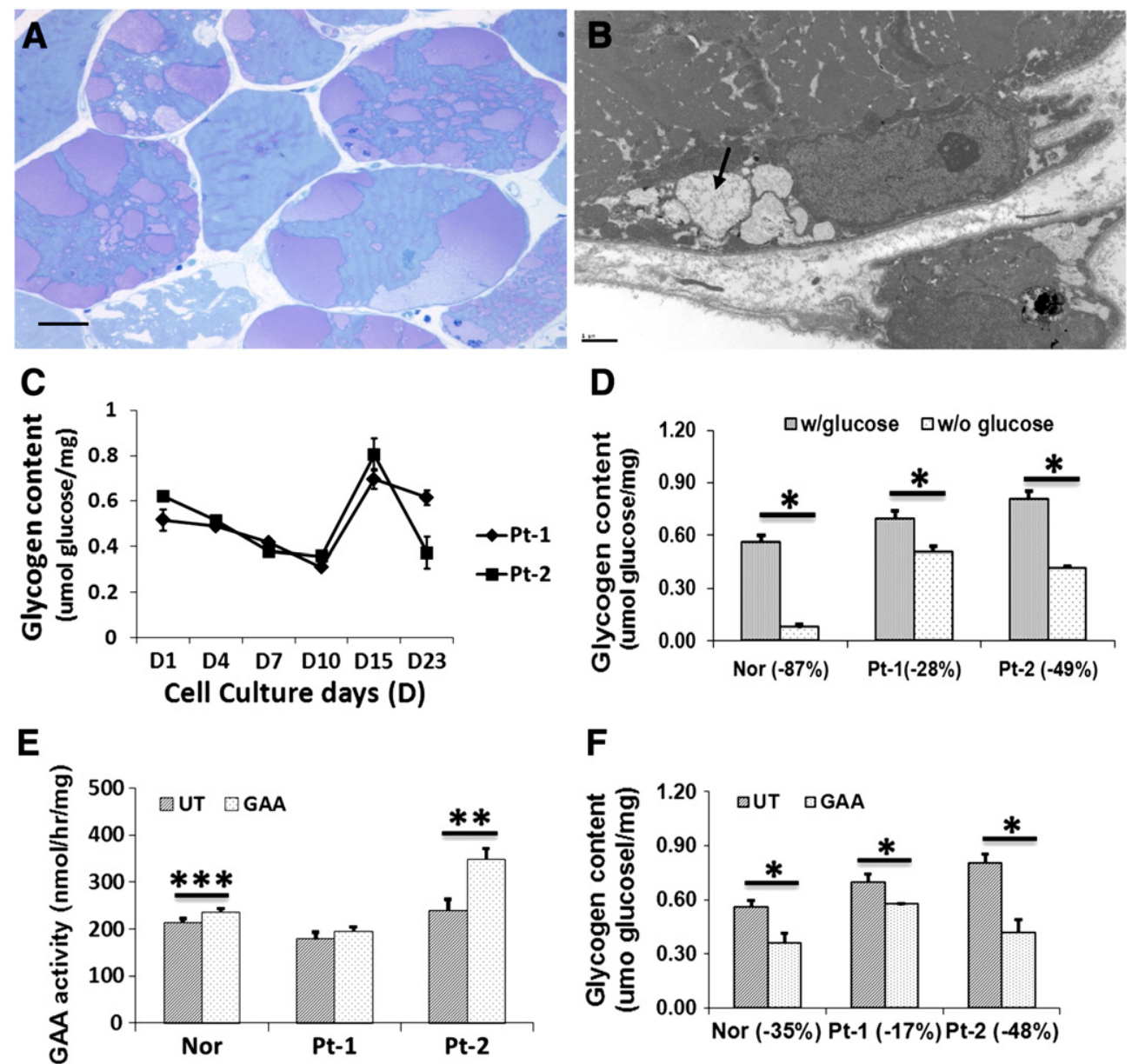

Fig. 1. Analyses of the skeletal muscle biopsies from two GSD IIIa patients, a 45-year-old male (Pt-1) and a 35-year-old female (Pt-2). (A) High-resolution light microscopy demonstrates that purple-staining glycogen is present as non-membrane-bounded cytoplasmic lakes within myocytes by Periodic Acid Schiff (PAS) staining (scale bar = 20 $\mu \mathrm{m}$ ). (B) Under EM, occasional lysosomal glycogen (arrow) was also seen in the myocytes (scale bar $=1 \mu \mathrm{m}$ ). (C) Glycogen accumulation pattern revealed that glycogen content was peaked at Day 15 in cultured patient muscle cells. (D) Glucose starvation experiment showed incomplete glycogen utilization in the muscle cells from both GSD IIla patients compared to a normal control subject (Nor). (E) GAA activity in normal and patient cells $48 \mathrm{~h}$ after adding rhGAA treatment. (F) rhGAA significantly reduced glycogen concentration in both normal and patient cells. Mean \pm standard deviation is shown in $\mathrm{C}-\mathrm{F}(\mathrm{n}=4)$. The significance of differences between two different groups was assessed using the two-tailed, equal variance student $T$-test $\left({ }^{*} \mathrm{P}<0.001 ;{ }^{* *} \mathrm{P}<0.01 ;{ }^{* * *} \mathrm{P}<0.05\right)$. 
Dietary interventions include control of hypoglycemia by cornstarch supplements or nocturnal gastric drip feedings and a high protein diet [4]. The benefit of a high protein diet or a combined ketogenic/ high protein diet in reversing cardiomyopathy was reported recently as a single case report $[9,10]$. Thus, there is no definitive therapy for this progressive condition. Challenges with direct ERT and gene therapy for GSD III include the lack of receptor-mediated GDE enzyme uptake and a suitable vector to deliver the large-sized $A G L$ gene.

ERT with rhGAA through mannose-6-phosphate receptor mediated enzyme uptake is an FDA approved therapy for Pompe disease. Although GSD III patients have normal GAA activity in muscle, excessive amounts of glycogen have been found not only in the cytoplasm (Fig. 1A) but also in the lysosomes (Fig. 1B) [11]. This suggests that the highly accumulated cytoplasmic glycogen is actively shuffled into the lysosomes and the "normal GAA" may not be sufficient to clear the lysosomal glycogen loads in GSD III. Therefore the up-regulation of "normal GAA" by providing it exogenously could be a novel treatment strategy for GSD III.

Primary human skeletal muscle cultures derived from human biopsy samples have become a useful tool to study the mechanisms of muscle metabolism underlying disease and evaluate therapeutic interventions [12-14]. In this study, we established an in vitro model for GSD III using primary skeletal muscle cultures from patients. We demonstrated that rhGAA significantly reduced glycogen accumulation in both normal and patient muscle cells possibly through the mechanism of glycogen shuffling from cytoplasm into lysosomes (Fig. 1F). This suggests that the glycogen lowing phenomenon by rhGAA is a general mechanism but not specific to situations with abnormal glycogen metabolism. This study provides the first insights into the role of lysosomal GAA in cytoplasmic glycogen clearance, especially when there is an increase in disease states.

In fact, after intravenous administration of rhGAA in Pompe mice, the majority of the enzyme was taken up by liver, followed by heart and skeletal muscle [15]. A similar rhGAA uptake pattern was also observed in patients with Pompe disease (unpublished data). Thus rhGAA could be more effective for glycogen clearance in liver than in muscle in vivo. This treatment could also be beneficial for patients with other GSDs. In future studies, we will test the efficacy of rhGAA treatment in a canine model of GSD IIIa [16].

\section{Conflict of interest}

P.S.K. reports receiving research and grant support from Genzyme. B.S., Y-T.C., and P.S.K. are listed as inventors on a Duke University pending patent application for the use of rhGAA in the treatment of GSD III and other GSDs excluding GSD II. To date, neither Duke University nor the inventors have received any money from rights associated with this pending patent. The other authors declare no conflict of interest.

\section{Acknowledgments}

We thank Dr. Deborah Muoio of Duke Medical Center for providing the normal human muscle cells. We also thank Ms. Dorothy Slentz for the technical assistance with the primary human muscle cultures.

\section{References}

[1] F. Huijing, Glycogen metabolism and glycogen-storage diseases, Physiol. Rev. 55 (1975) 609-658

[2] J.J. Shen, Y.T. Chen, Molecular characterization of glycogen storage disease type III, Curr. Mol. Med. 2 (2002) 167-175.

[3] Y.T. Chen, P.S. Kishnani, D.D. Koeberl, Glycogen storage diseases, in: D. Valle, A. Beaudet, B. Vogelstein, K. Kinzler, S. Antonarakis, A. Ballabio (Eds.), Scriver's Online Metabolic \& Molecular Bases of Inherited Disease, McGraw-Hill, New York, 2009.

[4] P.S. Kishnani, S.L. Austin, P. Arn, D.S. Bali, A. Boney, L.E. Case, W.K. Chung, D.M. Desai, A. El-Gharbawy, R. Haller, G.P. Smit, A.D. Smith, L.D. Hobson-Webb, S.B. Wechsler, D.A. Weinstein, M.S. Watson, Glycogen storage disease type III diagnosis and management guidelines, Genet. Med. 12 (2010) 446-463.

[5] C.M. Lynch, J. Johnson, C. Vaccaro, B.L. Thurberg, High-resolution light microscopy (HRLM) and digital analysis of Pompe disease pathology, J. Histochem. Cytochem. 53 (2005) 63-73.

[6] D.M. Muoio, J.M. Way, C.J. Tanner, D.A. Winegar, S.A. Kliewer, J.A. Houmard, W.E. Kraus, G.L. Dohm, Peroxisome proliferator-activated receptor-alpha regulates fatty acid utilization in primary human skeletal muscle cells, Diabetes 51 (2002) 901-909.

[7] S. DiMauro, W.J. Mellman, Glycogen metabolism of human diploid fibroblast cells in culture. II. Factors influencing glycogen concentration, Pediatr. Res. 7 (1973) 745-750.

[8] B.D. Sun, Y.T. Chen, A. Bird, A. Amalfitano, D.D. Koeberl, Long-term correction of glycogen storage disease type II with a hybrid Ad-AAV vector, Mol. Ther. 7 (2003) 193-201.

[9] V. Valayannopoulos, F. Bajolle, J.B. Arnoux, S. Dubois, N. Sannier, C. Baussan, F. Petit, P. Labrune, D. Rabier, C. Ottolenghi, A. Vassault, C. Broissand, D. Bonnet, P. de Lonlay, Successful treatment of severe cardiomyopathy in glycogen storage disease type III With D, L-3-hydroxybutyrate, ketogenic and high-protein diet, Pediatr. Res. 70 (2011) 638-641.

[10] A.I. Dagli, R.T. Zori, H. McCune, T. Ivsic, M.K. Maisenbacher, D.A. Weinstein, Reversal of glycogen storage disease type IIIa-related cardiomyopathy with modification of diet, J. Inherit. Metab. Dis. 32 (Suppl 1) (2009) S103-S106.

[11] F. Cornelio, N. Bresolin, P.A. Singer, S. DiMauro, L.P. Rowland, Clinical varieties of neuromuscular disease in debrancher deficiency, Arch. Neurol. 41 (1984) 1027-1032.

[12] J.R. Berggren, C.J. Tanner, J.A. Houmard, Primary cell cultures in the study of human muscle metabolism, Exerc. Sport Sci. Rev. 35 (2007) 56-61.

[13] I. Gati, O. Danielsson, T. Betmark, J. Ernerudh, K. Ollinger, N. Dizdar, Effects of inhibitors of the arachidonic acid cascade on primary muscle culture from a Duchenne muscular dystrophy patient, Prostaglandins Leukot. Essent. Fatty Acids 77 (2007) 217-223.

[14] M. Merickel, R. Gray, P. Chauvin, S. Appel, Cultured muscle from myotonic muscular dystrophy patients: altered membrane electrical properties, Proc. Natl. Acad. Sci. U. S. A. 78 (1981) 648-652.

[15] N. Raben, M. Danon, A.L. Gilbert, S. Dwivedi, B. Collins, B.L. Thurberg, R.J. Mattaliano, K. Nagaraju, P.H. Plotz, Enzyme replacement therapy in the mouse model of Pompe disease, Mol. Genet. Metab. 80 (2003) 159-169.

[16] H. Yi, B.L. Thurberg, S. Curtis, S. Austin, J. Fyfe, D.D. Koeberl, P.S. Kishnani, B. Sun, Characterization of a canine model of glycogen storage disease type IIIa, Dis. Model. Mech. 5 (2012) 804-811. 